\title{
"Em legítima defesa da \\ honra": a luta \\ contra a \\ naturalização da \\ violência contra \\ as mulheres
}

\section{Kathiusy Gomes da Silva*}

DOI: 10.11606/issn.2318-8855.v10i1p50-77

Resumo: O objetivo deste artigo é historicizar a conquista de espaços de defesa da mulher em situação de violência, enfatizando a Delegacia da Mulher (1985) e a Lei 11.340/06, popularmente conhecida como "Lei Maria da Penha". No artigo, procuramos relacionar as leituras com reportagens presentes na revista brasileira Veja para compreender como essa mídia construiu um discurso em relação à violência cometida contra as mulheres e como a luta de movimentos feministas reivindicando seus direitos e punições aos agressores foram importantes para as conquistas legais. Ao longo do artigo objetivou-se analisar como alguns casos marcaram a mídia brasileira, principalmente quando se tratava de violência contra mulheres conhecidas, como foi o caso do assassinato da socialite mineira ngela Diniz e da atriz de novela Daniela Perez.

Palavras-chaves: Violência Contra a Mulher; Lei 11.340; Revista Veja. 


\section{artigos}

“Em legítima defesa da honra"

\section{Introdução}

A violência contra as mulheres possui historicidade, e é importante discuti-la. O sentimento de posse dos homens sobre o corpo das mulheres, centrado na visão destas como propriedades, que em qualquer momento podem ser agredidas, castigadas e oprimidas; é fruto de uma estrutura social patriarcal que naturaliza tais atos de violência.

A partir do fim da década de 1970 , no Brasil, grupos feministas e movimentos de mulheres se envolveram de forma crescente em uma luta para dar maior visibilidade ao fenômeno da violência contra as mulheres, questionando, sobretudo, casos em que os agressores não eram julgados.

O objetivo deste artigo é historicizar a conquista de espaços de defesa da mulher em situação de violência, enfatizando a Delegacia da Mulher (1985) e a Lei 11.340/06, popularmente conhecida como "Lei Maria da Penha" e, em um segundo momento, analisar se apenas as conquistas legais são suficientes para diminuir as formas de violência praticadas contra as mulheres. Para tanto as fontes utilizadas nesse artigo são exemplares da revista $V e j a^{1}$. A pesquisa das fontes ocorreu em duas etapas: na primeira procuramos selecionar capas da revista Veja que traziam como manchete alguma referência às formas de violência cometidas contra as mulheres, recebendo atenção o aspecto imagético (fotos ou ilustrações) e os títulos das revistas. Inicialmente foram selecionadas 10 revistas. Em um segundo momento, as reportagens foram lidas e destacamos que, além de referências diretas a casos de violência contra a mulher que ganharam notoriedade no país por envolver pessoas

1 Os exemplares da revista Veja, desde a sua criação em 1968 até a atualidade, estão disponíveis no site: https://acervo.veja.abril.com.br/\#/editions Último acesso: 08/06/2018 


\section{artigos}

\section{Kathiusy Gomes da Silva}

conhecidas, também possuíam casos de violência urbana que tiveram como vítimas mulheres e meninas, e casos de violência sofrida por mulheres em outros países ${ }^{2}$, que foram associadas à violência política. . A metodologia utilizada é a análise documental, a partir da leitura de autores como Alessandra Pimental e Miriam Paula Manini.

De modo a criar subsídios para análises de tais fontes, contamos com autoras como Heleieth I.B. Saffioti, Wânia Pasionato Izumino, Maria Filomena Gregori, Ana Maria Colling, entre outras. Essas pesquisadoras analisam teorias que perpassam o estudo da violência como um componente das sociedades atuais, trazendo formas de interpretar e explicar a violência cometida contra as mulheres nos seus diversos âmbitos; bem como o avanço das leis que deveriam garantir o bem-estar físico e psicológico das mulheres; além de temas inter-relacionados a violência contra a mulher. São autoras fundamentais para a compreensão do avanço da legislação que se opõe a violência contra as mulheres desde a década de 1980, com o advento do SOS Mulher, bem como para compreender as relações de poder que envolvem a relação violenta entre mulheres e homens.

\section{Diferentes faces da violência}

Foi a partir dos anos de 1970 que os grupos feministas começaram a se apropriar das lutas pela conscientização e desnaturalização da violência contra as mulheres. Para tanto, procuraram o apoio do Estado a fim de elaborar leis e medidas protetivas para as mulheres. Já nos anos 1980, durante o processo de redemocratização do país após longos anos de ditadura civil-militar, em um momento

\footnotetext{
2 Duas edições: uma de 07/11/1984, que conta a história da morte de uma representante política indiana Indira Gandhi; e outra edição de 16/10/2013, que conta sobre as experiências de Malala, jovem paquistanesa que luta pelo direito à educação das mulheres.
} 


\section{artigos}

“Em legítima defesa da honra"

de mudanças sociais e políticas causadas pelos movimentos sociais, incluindo o crescimento de grupos de mulheres, conhecidas como "lobby do batom" que lutaram para incluir no texto da Constituinte as demandas e reivindicações por mais direitos das mulheres como direitos trabalhistas, igualdade entre homens e mulheres e um alargamento na perspectiva legal da constituição da família (LAGE; NADER, 2012).

É relevante destacar que a violência contra a mulher é um tema que sensibiliza a sociedade em qualquer época, mesmo nos períodos em que a violência era vista como forma de controlar o ímpeto feminino. Contudo, foi na virada da década de 1970 e 1980 que os casos de violência se tornaram uma demanda mais forte por parte das próprias mulheres.

Nesses anos, os objetivos dos grupos feministas eram dar maior visibilidade às agressões e elaborar formas de combatê-las. Já era perceptível a necessidade de um envolvimento da sociedade e do sistema jurídico nacional que concedesse apoio às mulheres conforme as suas necessidades. Uma conquista importante ocorreu em 1985 com o advento das Delegacias da Mulher, que se tornaram a principal política pública de combate à violência contra a mulher, além serem espaços que possibilitaram o desenvolvimento de pesquisas em relação às denúncias realizadas pelas mulheres, com destaque para aspectos como os detalhes dos crimes, informações sobre as vítimas, além da relação delas com os seus companheiros ou familiares (SANTOS; IZUMINO, 2005). Primeiramente é importante compreendermos a relação da violência como manifestação ou ausência de poder.

A violência é a forma mais bem constituída da manifestação de poder. O poder seria uma forma de submeter outro indivíduo a agir de acordo com as vontades daquele que o detém (SILVA, 2007). Para a autora, a violência necessita de 


\section{artigos}

\section{Kathiusy Gomes da Silva}

instrumentos para ser empregada, como um vínculo de convivência entre as pessoas. Nos casos de violência pode-se exemplificar: relação afetiva, empregatícia, relação de hierarquia empresarial, dentre outras. Sendo assim, a violência contra as mulheres se constituiria com base no poder de um homem ou mesmo de outra mulher sobre a mulher agredida, sempre mediada por esses vínculos. Ou seja, a relação de violência é marcada por uma diferença de poder.

\section{Violência: meios e formas}

Os estudos sobre a violência contra as mulheres na sociedade brasileira datam do final do século XVII, e abordam temas sobre as famílias e as suas relações. Um ponto comum desses estudos é o "retrato" que elaboram sobre a violência: “Ocorreria no espaço da casa - ambiente privado - e só era convertido para o meio público quando aconteciam os exageros" (IZUMINO, 2004, p.2). Nessa época, a violência era vista como forma de correção para o "bom desenvolvimento da ordem social", sendo comum homens agredirem as esposas e filhas a fim de controlá-las e manter o projeto de "lares ideais"; a violência só era mal vista quando prejudicava os afazeres do cotidiano.

As formas de violência foram se conjugando e organizando com o desenvolvimento da sociedade moderna, mas é uma presença constante no Brasil em diversas classes e etnias. A violência deriva dos papéis sociais impostos às mulheres e aos homens consolidados ao longo da história e reforçados pelas ideologias sociais, como o patriarcado, que induzem as relações violentas entre os sexos e indica que a prática desse tipo de violência não é fruto da natureza, mas de um processo de socialização das pessoas. Assim, violência contra as mulheres pode ser associada à violência de gênero (SANTOS; IZUMINO, 2005). 


\section{artigos}

“Em legítima defesa da honra"

É importante analisar que a violência não está presa a uma classe social, a exemplo disso tem-se o caso do assassinato de Ângela Diniz, morta por seu companheiro Doca Street, sendo os dois de classe abastada (Revista Veja, 24/10/1979). Podemos comparar as ocorrências de violência nos meios mais populares, como os que compõem a pesquisa de Lana Lage e Maria Beatriz Nader (2012). Nesta, as autoras pontuam o caso denominado de "A rainha do Baile" que ocorreu em 1905, em que Joanna Maria Ramos foi atacada ao sair da gafieira por um homem, com quem a vítima não tinha nenhuma relação, mas que estava enciumado por conta das investidas de outro homem (LAGE; NADER, 2012). Esses dois pleitos, que são constituídos por personagens de classes distintas, exemplificam que a violência faz parte dos diversos meios sociais, o que as diferenciam é a forma de agir das vítimas, que mudam de acordo com sua classe, como destaca Izumino:

(...) no caso específico da violência contra a mulher, alertou-se para o fato de que setores mais privilegiados da população, quando confrontados com estes conflitos contam com agentes e serviços que permitem sua negociação e resolução de forma "privada", por exemplo, advogados, terapeutas e médicos particulares, sem precisar enveredar pela via policial-judicial. Dito de outra forma significa dizer que a violência doméstica não é resultado da pobreza, mas sua publicização é resultado da carência de direitos, entre eles o direito de ter acesso a serviços especializados para o atendimento de problemas desta natureza (IZUMINO, 2004, p.4).

Izumino (2004) destaca as diferentes realidades sociais, pois enquanto uma mulher de classe alta pode sair da situação de agressão através de representantes jurídicos conhecidos na área do Direito e, posteriormente, fazer um acompanhamento com uma equipe de médicos para lidar com a situação, as mulheres das classes populares têm que passar por um processo duro para receber 


\section{artigos}

\section{Kathiusy Gomes da Silva}

ajuda, como realizar o exame de corpo de delito, que pode ser um constrangimento, lidar com o inquérito se tem por objetivo conseguir um acompanhamento de médicos pelo Sistema Único de Saúde e, em algumas situações, não tendo para onde ir, são acolhidas em casas de apoio.

O tipo de violência no caso de Ângela Diniz e de Joanna Maria Ramos é a violência física seguida de morte das vítimas. Contudo, é importante compreender que existem outras formas de violência que são analisadas de acordo com a sua qualificação: $1^{\circ}$ do contexto onde ocorre (violência doméstica); $2^{\circ}$ pelo tipo de relacionamento entre as pessoas envolvidas (violência familiar, violência conjugal); $3^{\circ}$ pelo sexo dos envolvidos (violência contra a mulher, violência de gênero); e $4^{\circ}$ pelo tipo de ato praticado (feminicídio - assassinato de mulheres ou violência sexual) (IZUMINO, 2002 apud IZUMINO, 2004).

Um engano comum ocorre quando se caracteriza a violência doméstica como violência familiar (intrafamiliar). Isso ocorre pois se confunde o espaço da casa com a ideia de compartilhar o lar com a família. A diferença é que a primeira ocorre no interior do lar entre membros da família (mulheres e homens, pais e filhos, jovens e idosos) ou pessoas agregadas a esta, como empregadas domésticas. O segundo caso não ocorre no interior do lar e é resultado das ações dos membros de uma única família.

No Capítulo II da Lei $11.340 / 06^{3}$ (Lei Maria da Penha), no Artigo $7^{\circ}$, estão estipuladas as formas de violência doméstica e familiar contra a mulher, como física, psicológica, sexual, patrimonial e moral. A Lei faz essa especificação com o intuito de

3 Para mais informações sobre a lei indico o site: http://www.planalto.gov.br/ccivil_03/_ato20042006/2006/lei//11340.htm Último acesso: 08/06/2018. 


\section{artigos}

“Em legítima defesa da honra"

facilitar o procedimento do inquérito, além de exemplificar as diversas situações de violência que as vítimas podem estar envolvidas para que estas consigam se identificar nas situações, sendo um incentivo para procurar ajuda.

Os crimes mais comuns praticados contra as mulheres são a violência física, moral e psicológica. A violência conjugal é a que possui os maiores índices de absolvição dos acusados (SOIHET, 2002), justamente por retomar a situações como crimes pela "legítima defesa da honra", além de ser comum nesses casos arruinar a imagem das vítimas, transformando-as em culpadas por provocar os seus algozes.

Até o ano de 2005, quando o adultério deixou de ser crime no Brasil, a condenação legal feminina como adúltera legitimava a violência conjugal - incluindo o assassinato em "legitima defesa da honra" como forma de punição privada, praticada por maridos supostamente ou de fato traídos. A honestidade da mulher era ligada à sua conduta sexual e legitimada pela ideologia patriarcal: "a dominação masculina fez do espaço do lar um locus privilegiado para a violência contra a mulher" (LAGE; NADER, 2012, p. 288). O comportamento feminino considerado fora do padrão, estabelecido pela sociedade para as denominadas "mulheres honestas", justificava a violência contra as mulheres consideradas desonestas que "não possuíam pudor" para viver em sociedade. Assim, a violência era aplicada como castigo e as agressões eram atos medidos conforme a situação e a necessidade de disciplinar.

Entre os instrumentos normativos brasileiros, destacam-se as Ordenações Filipinas (Código Filipino), legislação do período colonial que permaneceu vigente no Brasil até o desenvolvimento do Código Criminal Brasileiro, em 1830. A Ordenação Filipina permitia ao marido castigar sua mulher ou matá-la em caso de adultério ou por suspeitas - muitas vezes o ato ocorria sem a comprovação da traição (COLLING, 


\section{artigos}

Kathiusy Gomes da Silva

2015). Também era permitido aos homens o enclausuramento forçado da esposa e filhas. Apesar da elaboração do Código Criminal Brasileiro de 1830, a situação da mulher vítima de violência continua naturalizada, principalmente com o Código Civil de 1916, que disseminou discriminações contra a mulher, tratando-a como um ser inferior ao homem.

O Código civil de 1916 só foi superado com o advento do "Estatuto da Mulher Casada" (Lei 4.121 de 1962), no qual a mulher já não era vista como incapaz, que necessitava da assistência do marido. Outra mudança é que, pela Lei de 1962, a mulher que se casasse pela segunda vez tinha a tutela dos filhos do primeiro casamento, sem interferência do novo marido (CORTÊS, 2012).

Foi só a partir dos anos 1990 que a categoria violência de gênero passou a ser utilizada, nos discursos feministas, como sinônimo de violência contra a mulher, especificando que essa forma de violência era praticada contra a mulher por ela ser mulher. Essa nova qualificação considera a intencionalidade do controle do corpo e do comportamento feminino por parte dos homens, e as formas que a sociedade reproduzia as ideias de submissão das mulheres - ideias herdadas da ideologia patriarcal. Izumino destaca em seu texto:

Teoricamente, a incorporação da categoria de gênero aos estudos sobre a violência contra a mulher apresentou-se como uma alternativa à teoria do patriarcado que define a relação entre os sexos a partir do binômio dominação masculina-submissão feminina. Ao descrever a violência contra a mulher como violência de gênero, aquela passou a ser analisada através de atributos como a construção social dos papéis masculino e feminino e o poder inscrito nas relações entre os sexos nas sociedades (IZUMINO, 2004, p.5) 


\section{artigos}

“Em legítima defesa da honra”

Nota-se que, com a incorporação da categoria gênero, ocorre um resgate das noções patriarcais, mesmo que nessa época as teorias do patriarcado já não conseguissem mais explicar o arranjo dos relacionamentos modernos.

\section{OS CASOS QUE MARCARAM O PAÍS E O DESENVOLVIMENTO DAS LEIS}

Ao homem foi atribuído o poder de controlar as pessoas que viviam sob o seu teto, principalmente quando se tratava de mulheres (esposas e filhas). Como portador do direito à vida ou morte, a ele foi atribuído o poder de matar a companheira em caso de traição, com a justificativa de legítima defesa da honra" (PINTO, 2003).

Foi com esta justificativa que o réu Doca Street assassinou sua companheira Ângela Diniz e foi absolvido em primeira instância. O crime ocorreu em 30 de dezembro de 1976, em Armação dos Búzios. Ângela Diniz, aos 32 anos, mãe de três filhos, levou três tiros no rosto e um na nuca, disparados pela arma de Doca Street (42 anos). O comportamento da vítima foi descrito como uma afronta aos padrões femininos da época, e serviu como base para a defesa do assassino, sendo uma imagem deturpada conforme os interesses da defesa e da mídia, como destacado em:

A defesa construiu sua tese com base na ideia de que Doca Street teria agido "em legítima defesa da honra", argumento baseado na tipificação do adultério como crime. Ângela foi descrita no tribunal como promíscua e bissexual, uma verdadeira "Vênus lasciva", termo usado pela defesa, que a acusava de manter casos com outros homens e mulheres (LAGE; NADER, 2012, p.297)

O ocorrido, conhecido popularmente como "O crime da Praia dos Ossos", 


\section{artigos}

\section{Kathiusy Gomes da Silva}

ganhou os jornais, principalmente após o acusado ser beneficiado com a suspensão condicional da pena conforme o artigo 696 do Código de Processo Penal. O julgamento virou praticamente um programa de auditório devido à presença da imprensa dentro e fora do fórum, sendo um caso que foi marcado pela divulgação. “À porta do fórum uma comitiva de mulheres pedia a absolvição de Doca e louvava sua conduta com cartazes" (Revista Veja, 24/10/1979, p. 114). O apoio popular e principalmente feminino ao caso foi grande, justamente por Doca representar o homem burguês branco, honrado e tradicional da época, que mesmo cometendo um crime por machismo, ainda foi ovacionado pela população. O título da reportagem da revista Veja que traz a imagem de Doca Street na capa é "Doca vai, mata e vence". Ao longo dessa reportagem têm-se diversas visões sobre o caso: o interesse dos advogados em ganhar, a deterioração da imagem de Ângela Diniz, a defesa tentando difundir a imagem de Doca como um explorador de mulheres, o caso como uma forma de reproduzir os ideais da sociedade, dentre outras. Referindo-se ao fórum de Cabo Frio a reportagem destaca: “Por ele passaria não só Doca Street e Ângela Diniz, mas um estilo de vida. Precisamente esse estilo foi contornado" (Revista Veja, 24/10/1979, p. 116).

Os dois repórteres que escreveram a matéria (Artur Xexéo e Augusto Nunes) destacaram a "falsa moralidade" da sociedade brasileira que deixou livre um homem que matou a sangue-frio sua companheira pelo simples fato dela não se submeter a suas vontades. Os repórteres salientaram que o júri era composto em sua maioria por homens (que de certa forma podem ter se compadecido com a situação do seu "igual"), confirmando uma tendência nacional - que ainda se perpetua na atualidade de manter em liberdade pessoas abastadas, como destaca a reportagem no trecho: “Cabo Frio produziu também a mais sensacional libertação de um homem que mata 


\section{artigos}

“Em legítima defesa da honra"

mulher, além de confirmar a tendência para não se mandar às penitenciárias os habitantes do mundo elegante" (Revista Veja, 24/10/1979, p. 119).

A reportagem posterior ao dossiê do julgamento do caso de Ângela Diniz (denominada como "A defesa da fortuna", Revista Veja, 24/10/1979, p.120) destaca justamente a temática de como representantes da classe alta, principalmente os homens, conseguem sair impunes de atos criminosos, com o título "A defesa da fortuna - Cinco júris de crimes passionais: quatro réus ricos saem livres; o pobre, não". A reportagem aborda cinco casos: 1) Rica mata Rica caso de uma mulher traída que mata a nova companheira do marido com a justificativa "pela integridade do lar" (31 de março de 1964); 2) Rico mata rica, ex-marido mata a mulher com dois tiros no peito e um na cabeça depois de tentar a reconciliação e a mulher negar, este foi justificado pela já mencionada "em legítima defesa da honra"; 3) Rico mata pobre, em 1973 o primeiro companheiro de Ângela Diniz, Artur Mendes mata o lavador de carro João Avelino, com três tiros com a justificativa que o homem estava ameaçando o casal - como no caso de Diniz os mortos são condenados pelo júri e os vivos saem perdoados, Mendes foi absolvido; 4) Rica mata rico, em 1975 a ex-mulher Elza Leonetti pede ao ex-companheiro Roberto Lee que reconhecesse a paternidade da filha, com a recusa, depois de uma agressão, a mulher saca uma arma e mata o homem com dois tiros. Elza em entrevista fala que Doca Street deveria ter sido condenado pelo assassinato de Ângela Diniz, pois matou por machismo, e ainda destaca que a sua condenação, de 6 anos, foi por discriminação de sexo; e 5) Pobre mata pobre, um comerciante mata a ex-companheira a facadas depois de discussão, motivado pelo abandono do companheiro depois de 20 anos de relacionamento, mesmo utilizando a justificativa de "legítima defesa da honra", pois comprovou que a mulher o traíra. O homem pobre foi condenado por unanimidade. 


\section{artigos}

Kathiusy Gomes da Silva

A análise desses cinco casos demonstra que o dinheiro é um atenuante de pena, seguido pelo sexo. Algo que precisa ser salientado é que o terceiro caso, da morte de João Avelino, foi retomado no julgamento de Doca Street, pois na época existia a hipótese de que o lavador de carros foi morto por ter um caso com Ângela. Essa história serviu como mais uma "prova" de que Ângela era uma mulher sem honra a ponto de causar a morte de um homem por seus desejos sexuais incontroláveis.

O apelo de grupos feministas levou Doca Street a um novo julgamento, sendo que este acabou sendo condenado a 15 anos de prisão em regime fechado, em 1981, mas depois de 3 anos conseguiu liberdade condicional. Da frase de Doca, "Matei por amor", proferida pelo assassino após sua absolvição no primeiro julgamento, nasceu o slogan "Quem ama não mata", amplamente divulgado pelas feministas através de uma campanha que teve grande participação popular (LAGE; NADER, 2012). Esse slogan ainda é utilizado pela causa com o intuito de conscientizar a população para lutar contra a violência contra a mulher.

\section{Delegacias Defesa da mulher (DDM)}

A primeira Delegacia de Defesa da Mulher (DDM) - inaugurada em 6 de agosto de 1985 na cidade de São Paulo -, surgiu como um resultado das lutas dos grupos feministas que denunciaram os inúmeros casos de mulheres que estavam sendo mortas por seus parceiros íntimos, os quais ficavam impunes. Além da impunidade, os grupos feministas denunciavam o descaso com que a polícia tratava os casos de violência doméstica e sexual (PASINATO; SANTOS, 2008). A primeira DDM foi criada por meio do Decreto 23.769, que estabeleceu que caberia a estas delegacias investigarem os delitos contra a pessoa do sexo feminino, previsto no Código Penal. 


\section{artigos}

“Em legítima defesa da honra"

Até o surgimento da DDM, a especialização do trabalho policial não tinha como critério a identidade da vítima. Atualmente essas delegacias são denominadas DEAM - Delegacia Especializada no Atendimento à Mulher.

Em 1985, também foi criado o Conselho Nacional dos Direitos da Mulher (CNDM), o primeiro órgão do Estado brasileiro a tratar especificamente dos direitos das mulheres. A exemplo dos conselhos estaduais, o CNDM tinha o poder de formular propostas de políticas para as mulheres, contudo não tinha poder para executar e monitorar políticas públicas, sendo muito importante no processo de elaboração da Constituição Federal de 1988, contribuindo para a inclusão das demandas feministas no texto constitucional (ALVAREZ, 1990 apud PASSINATO; SANTOS, 2008).

No que tange às DEAM, ocorreu uma grande discussão em relação ao seu modelo de funcionamento, principalmente em relação a três aspectos: 1) que serviço deveriam oferecer, isto é, se deviam restringir-se apenas a serviços policiais ou se deviam incluir, no espaço da delegacia, acompanhamento de assistentes sociais e serviços psicológicos; 2) que papel deveriam desempenhar os serviços policiais - com destaque para a dificuldade dos policiais (homens) lidar com as vítimas, se deveriam orientar/aconselhar a vítima buscar apoio de outros serviços (prestados pelo governo ou ONGs); e 3) que crime deveriam investigar, ou seja, só os tipos de violência no âmbito doméstico ou abranger para os diversos tipos de violência que são cometidos contra as mulheres. Com base nessas problemáticas para efetivação dos serviços, não se desenvolveu um único modelo de DEAM devido à diversidade de práticas policiais e, principalmente, a diversidade de sujeitos e situações que os funcionários dessas delegacias deveriam lidar cotidianamente. Todavia, existe um modelo considerado ‘base' que inclui serviços policiais de investigação e abertura de inquéritos, além de 


\section{artigos}

Kathiusy Gomes da Silva

espaços de aconselhamento e de mediação de crimes, atendendo as ocorrências praticadas por parceiros ou ex-companheiros de mulheres, bem como crimes sexuais. Nesses espaços não existe um serviço de acompanhamento psicossocial próprio, sendo a vítima encaminha a outros órgãos públicos (SILVA, 2007).

Desde o desenvolvimento das DEAM a orientação do governo federal recomendava que os funcionários das delegacias da mulher fossem preferencialmente mulheres, contudo a carreira de policiais e de delegados são predominantemente masculinas. A composição desigual reflete na composição das equipes nas delegacias da mulher, que possui um número menor de policiais mulheres. Essa situação abre espaço para o preconceito e o machismo praticado por policiais homens contra as mulheres que procuram as delegacias em busca de ajuda, “muitas vezes a polícia transformava o interrogatório das vítimas numa verdadeira tortura, desconfiando da inocência da mulher e até manifestando uma certa cumplicidade com o comportamento do agressor" (COLLING, 2015, p.12).

É comum estigmatizar as mulheres indagando, em caso de violência doméstica, se esta provocou o companheiro, se cometeu adultério, dentre outras. Em casos de violência sexual são comum indagações como local em que a vítima estava, tipo de roupa, se provocou o homem de alguma forma, motivo de estar sozinha e/ou fora de casa em determinado horário, dentre outras. Assim, nota-se que, independente do espaço, horário ou situação, as mulheres podem ser questionadas se deveriam frequentar determinados ambientes desacompanhadas, como se não tivessem o direito em lei de ir e vir e frequentar qualquer ambiente.

Apesar das falhas existentes no serviço prestado pelas DEAM, estas continuam prestando o atendimento considerado mais adequado aos casos de violência contra 


\section{artigos}

“Em legítima defesa da honra"

as mulheres, pois nas delegacias não especializadas esses casos teriam que competir com aqueles considerados legítimos do trabalho policial: roubos, furtos, tráfico de drogas, assassinatos, dentre outros (LAGE; NADER, 2012, p.301).

No contexto da virada da década de 1980 para 1990, as mulheres ganharam o direito de serem vistas como vítimas e de receber o tratamento do Estado como qualquer pessoa agredida (PINTO, 2003), com isso a mulher identificou as acusações nas DEAM como um espaço de poder, como destaca Rifiotis:

Na realidade, pelo que se pôde observar, a instituição cumpre um importante papel de acolha e processamento, servindo de apoio para as mulheres vitimadas. Assim, pode-se afirmar que os serviços de polícia são ressignificados. Fundamentalmente, observei um uso da queixa (Boletim de Ocorrência) como mecanismo de ameaça e renegociação de pactos conjugais; e da intimação, por sua vez, apropriada como mecanismo para criar o 'diálogo' e o reconhecimento da 'culpa', dar o 'susto' e colocar o companheiro no 'bom caminho'. Em síntese, a DM seria um espaço de recepção, acolha de queixas, de exercício de controvérsia apoiado na figura da autoridade policial (RIFIOTIS, 2003, 2004 apud RIFIOTIS, 2008, p. 227).

Rifiotis destaca que as mulheres passaram a se apropriar dos serviços prestados pelas delegacias especializadas com o intuito de salvar ou endireitar os relacionamentos com seus parceiros, então as delegacias passaram de espaços de justiça para de reconciliação, por isso é comum a retirada e aberturas de novas queixas pela mesma mulher. Em depoimento à revista Veja, a escrivã Márcia Bezerra Mendonça destaca: “No fundo, a mulher nos procura não tanto para denunciar um crime, mas para ver se a polícia consegue modificar o temperamento violento do parceiro" (revista Veja, 01/07/1998, p.83). 


\section{artigos}

Kathiusy Gomes da Silva

Mesmo que utilizadas mais como mediadores de relacionamentos do que como espaço de justiça, os policiais que trabalham nas DEAM necessitam de uma capacitação para aprender a lidar com crimes relacionados à violência contra as mulheres. Essa qualificação se dá através de cursos, palestras e seminários que envolvam a capacidade de lidar com pessoas traumatizadas; esses métodos podem ser incorporados às disciplinas de cursos de formação de policiais. Apesar dessa necessidade, a realidade das delegacias de mulheres é de funcionários despreparados, que não conhecem os passos dos trâmites legais para salvaguardar o bem-estar das vítimas - não diferenciam os casos que necessitam de medidas cautelares, não sabem para onde encaminhar as vítimas após a abertura dos inquéritos, dentre outras situações (PASSINATO; SANTOS, 2008).

Pela falta de qualidade na capacitação ofertada aos policiais para lidar com vítimas de violência, o serviço prestado acaba sendo considerado insatisfatório, reforçando a ideia de trabalho realizado com "má vontade" por parte dos policiais e descaracterizando o atendimento das DEAM. Contudo, mesmo com as falhas e dificuldades para executar os serviços as delegacias de defesa da mulher ainda são consideradas a iniciativa brasileira mais eficaz contra a violência, pois, em teoria, alia a função de combate, prevenção e proteção das mulheres.

\section{Casos de violência}

O capítulo III, denominado "Da Segurança Pública”, da Constituição Federal de 1988, assegura que é dever do Estado brasileiro proporcionar a segurança aos cidadãos, e, em caso de infrações penais e crimes, a polícia (que melhor se encaixar

\footnotetext{
4 Constituição Federal disponível em: http://www.planalto.gov.br/ccivil_03/constituicao/constituicaocompilado.html. Último acesso em: 01/06/2018
} 


\section{artigos}

“Em legítima defesa da honra"

no delito) deve ser responsável por manter a ordem e levar a justiça à população (§ $7^{\circ}$, Constituição Federal, Art. 144). Contudo, no Brasil, em situação de violência contra a mulher, comumente ocorrem dois tipos de situações: a primeira é a impunidade, que se perpetuariam se as famílias das vítimas de caso de assassinatos não lutassem por justiça a suas parentes; a segunda é o longo caminho que as vítimas de agressão têm que trilhar em busca de ajuda e justiça.

Como exemplo da primeira situação, tem-se o caso da escritora Glória Perez que, em entrevista à revista Veja de 10/02/1993, afirma que não vai descansar até fazer justiça pela morte de sua filha, Daniela Perez, que foi brutalmente assassinada com dezesseis estocadas por um colega de trabalho. Na reportagem intitulada “Dias de ira e dor" a jornalista Eliane Azevedo destaca:

Dois dias depois da morte de Daniela, sua mãe já estava na ativa. Escrevia a novela, consolava seus outros dois filhos (...) e, mais do que tudo, procurava maneiras de incriminar e fazer com que a Justiça puna com rigor o ator Guilherme de Pádua e sua mulher, Paula Nogueira de Almeida Thomas. Ela está colhendo depoimentos de pessoas que conviveram com Guilherme e Paula, para mostrar que sempre foram pessoas mesquinhas, cínicas e perversas, que planejaram em detalhe o assassinato. Também controla de perto a movimentação dos advogados, para evitar o relaxamento da prisão do casal e fazer com que o processo ande rápido. É uma atividade incessante, aparentemente inesperada numa mulher ferida tão fundante. Para os artistas e psicólogos, no entanto, a fortaleza de Glória Perez, a sua recusa em calar-se e recolher-se, segue um padrão explicável (Revista Veja, 28/12/1992, p.64-65).

O padrão de Glória Perez é explicável, pois sem a insistência dela em fazer justiça pelo assassinato de sua filha, mesmo a vítima sendo uma artista de novela com grande destaque na mídia, o caso arrastou por muito tempo nos tribunais 


\section{artigos}

\section{Kathiusy Gomes da Silva}

ajudando os dois réus a receberem penas 'leves', já que quanto mais tempo se passar entre o crime e o julgamento, maiores são as chances do júri ser benevolente ao aplicar a pena, "se o julgamento for antes de outubro, os dois devem ser condenados", diz um experiente advogado carioca, "se for entre novembro e dezembro, crescem as chances de um deles ser absolvido. Ficando para o ano que vem, torna-se imprevisível seu desfecho" (Revista Veja, 10/02/1993, p. 69). Glória Perez batalhou para proteger sua filha contra a impunidade jurídica brasileira.

O assassinato de Daniela foi motivado por ciúme desmedido da mulher do ator Guilherme de Pádua (par romântico da atriz na novela que os dois estavam gravando), que influenciou o ator a matar uma jovem considerada por todos gentil e amável. O ciúme incontrolável que leva pessoas "normais" a tomar atitudes violentas é tema da revista Veja de 13/11/1996. Nessa reportagem a jornalista Vilma Gryzinski destaca diversos casos que foram motivados pelo ciúme incontrolável dos agressores. Na edição da revista, denominada de "A fúria do ciúme", a psiquiatra Guida Palomba afirma: "A pessoa fica escrava do sentimento, prisioneira de um pensamento doentio. O fato de a mulher usar batom já é motivo para desconfianças injustificáveis" (revista Veja, 13/11/1996, p. 124).

A segunda situação comum no Brasil é a busca incessante por ajuda e justiça que as vítimas de agressão têm que enfrentar: situações de temor não só por sua própria vida, mas de seus filhos e familiares, ameaças, perseguição, entre outras. A edição da revista Veja de 1998, intitulada “Covardia: o terror das mulheres que vivem com homens espancadores", apresenta a reportagem especial "Face do silêncio: a violência doméstica atinge não apenas a mulher, mas toda a sociedade", escrita pela jornalista Dorrit Harazim, que destaca como a violência contra a mulher se tornou um sinônimo de violência doméstica, além disso, defende que a violência contra a mulher 


\section{artigos}

“Em legítima defesa da honra"

não cabe mais no espaço privado e já é um problema social, precisando de iniciativas públicas para apresentar melhoras.

A revista de 01/07/1998 apresenta que o lugar mais perigoso para a mulher é em casa, pois no ambiente privado as chances de a mulher sofrer alguma agressão são nove vezes maiores do que nas ruas (Revista Veja, 01/07/1998, p. 81). Ainda nesta edição estão presentes depoimentos de titulares em DEAM, tanto mulheres quanto homens. Nessas declarações pode-se analisar como existe uma visão preconceituosa entre os próprios policiais, homens, em relação às delegacias especializadas, como no trecho:

Proteção para a mulher agredida só existe no seriado Dama de Ouro, em que a delegada americana Katy Mahoney resolvia tudo. A Delegacia de Mulheres, da TV Globo, também glamourizou demais, com aquela coisa de cafezinho e tapinha no ombro. Na prática não é nada disso". Não é mesmo. A começar pela imagem que a própria corporação tem do policial alocado em uma Delegacia da Mulher. "Quando informei meus colegas que eu vinha para cá", lembra Assis, "foi como se eu dissesse que tinha caído na vida. "Tá lá de castigo?", perguntam até hoje. Troquei o poder da truculência por isso aqui, onde o marginal é um pai de família. (Depoimento de Oswaldo de Assis, 41 anos, revista Veja, 01/07/1998, p.83).

Nesse trecho nota-se que o policial Assis analisa os agressores não como criminosos, mas como "pais de família", sem considerar as atitudes violentas que esses homens praticam contra as mulheres. Outro depoimento que ajuda a compreender a situação complexa que envolve a perpetração da violência contra as mulheres é o que segue:

O sofrimento da minha cunhada começou um dia depois do casamento. Ela apanhou do marido ainda na lua-de-mel. Mas, por medo e vergonha, ela dizia 


\section{artigos}

\section{Kathiusy Gomes da Silva}

que havia caído ou se batido. A família demorou a saber o que se passava, mas ela fez várias denúncias à polícia. Dezenas de boletins de ocorrência e laudos do Instituto Médico Legal que comprovaram as agressões que ela sófria não foram suficientes para colocar o Ismael [Haick] (ex-marido de Núbia) na cadeia. Fui uma testemunha do terror que esse homem impôs a toda família. Um dia, já depois da meia-noite, recebi um telefonema da babá dos meus sobrinhos dizendo que Núbia não havia chegado em casa. Na hora eu pensei: meu Deus, perdemos a Núbia. Na manhã seguinte fomos à delegacia e soubemos que um corpo de mulher havia sido encontrado num matagal. Quando reconheci o corpo no IML, fui tomado pela revolta. Todas as denúncias que a Núbia apresentou à polícia não serviram de nada para evitar que ela fosse morta. (revista Veja, 15/03/2006, p. 80, grifo pessoal).

No depoimento de Nelson Furtado, cunhado da professora Núbia Conte Haick, de 42 anos, assassinada pelo ex-marido, pode-se notar que mesmo com as DEAM, as mulheres eram agredidas, justamente por não existir uma legislação específica para tratar da violência contra a mulher, assim viu-se a necessidade de desenvolver novas iniciativas que salvaguardassem o bem-estar físico e psicológico das mulheres.

\subsection{Lei 9.099 de 1995 e Lei 11.340/06}

A criação dos Juizados Especiais Criminais (JECRIM) não tem relação específica com as ocorrências de violências contra a mulher. Sua definição legal está relacionada à necessidade de desafogar o sistema judiciário brasileiro. Os Juizados desenvolviam suas atividades visando a celeridade, a economia processual, a informalização da justiça e a aplicação de penas alternativas à comum restrição da liberdade. Os casos que poderiam ser julgados nos JECRIM eram os que a pena máxima atingia um ano de detenção, chamados de "crimes de menor potencial ofensivo" (IZUMINO, 2004).

Apesar de não ter sido elaborada para penalizar os crimes praticados contra as 


\section{artigos}

“Em legítima defesa da honra"

mulheres, a definição legal das JECRIM acabou abrangendo quase que a totalidade das ocorrências que são registradas nas DEAM. A Lei 9.099, aplicada a casos de violência contra a mulher, reduz a capacidade de investigação policial e institui a aplicação de penas substitutivas, como pagamento de cestas de alimentos e multas de valores irrisórios pelos agressores.

Os grupos feministas se mobilizam contra a Lei 9.099, argumentando que tal lei banalizou a violência contra a mulher por classificar esses atos como crimes de "menor potencial ofensivo". Além de encaminhar os casos para o desfecho que tem como principal objetivo o acordo entre as partes. Para casos de mulheres que não desejam a prisão dos seus agressores, mas só um rearranjo dos seus relacionamentos, a Lei 9.099 se torna eficaz, pois o caso é concluído em pouco tempo e com ambas as partes livres. O contrário já não é razoável, como demonstra a revista Veja, edição de 2006, sobre a Lei 9.099:

Ela é bem-vinda para desafogar o congestionadíssimo Judiciário brasileiro e funciona muito bem para brigas entre vizinhos, por exemplo, que comportam compensações financeiras. Mas não para os casos que envolvem a complexa teia de violência que se instala na relação conjugal. Nessas situações, em que a mulher teve de reunir todas as forças para fazer a denúncia e frequentemente está sendo ameaçada pelo agressor, propor acordo é praticamente coagi-la a recuar. E prever o pagamento de cestas básicas como pena para o agressor aproxima-se do escárnio. "A sensação que existe em relação a esses crimes é de total impunidade", diz Jacira Melo, diretora do Instituto Patrícia Galvão, de São Paulo, ONG que desenvolve projetos sobre direitos da mulher (revista Veja, 15/03/2006, p.81).

Em relação à violência contra a mulher, a Lei 9.099 criou empecilhos para as mulheres agredidas que buscam as DEAM, disseminando o sentimento de 


\section{artigos}

\section{Kathiusy Gomes da Silva}

impunidade e falta de apoio do Estado. A realidade das mulheres que sofrem agressões físicas e psicológicas só se modificou com o advento da Lei 11.340. A reportagem da revista Veja de 2006 foi lançada antes da votação da lei, mas o projeto foi comentado na reportagem:

O projeto foi redigido com base em discussões feitas em todo o Brasil com entidades femininas e traz como principal mudança a criação de juizados especiais de violência doméstica contra a mulher, a exemplo dos que existem para crianças, adolescentes e idosos. Entre outras medidas, o projeto elimina o pagamento de cestas básicas (admite como pena alternativa apenas a frequência a serviços de reabilitação pelo agressor) e estabelece mecanismos de proteção à vítima. (...) O fato de a violência contra a mulher ocorrer dentro de um quadro cultural bem delimitado que a torna "natural" aos olhos da sociedade, não a transforma em ato justificável. (revista Veja, 15/03/2006, p. $82)$.

A Lei 11.340 foi sancionada no dia 7 de agosto de 2006, mas só entrou em vigor no dia 22 de setembro de 2006, mesmo ano da publicação da revista. A Lei, conhecida popularmente como "Lei Maria da Penha" recebeu esse nome em homenagem à Maria da Penha Maia Fernandes, vítima de violência doméstica e dupla tentativa de homicídio por parte de seu marido Marco Antônio, que em 1983 a deixou paraplégica. Entre a data da primeira agressão e a prisão do criminoso transcorreram 19 anos e 6 meses, sendo que ao final o réu permaneceu apenas 2 anos detido. A morosidade da Justiça foi uma das causas para o caso se alongar por tanto tempo (ROCHA, 2009).

Em 1998, Maria da Penha juntamente a grupos feministas, o Centro para a Justiça e o Direito Internacional (CEJIL) e o Comitê Latino-Americano e do Caribe para a Defesa dos Direitos da Mulher (CLADEM), encaminharam à Comissão Interamericana de Direitos Humanos da OEA uma petição contra o Estado brasileiro 


\section{artigos}

“Em legítima defesa da honra"

relativo à violência sofrida por ela. A denúncia do caso foi uma espécie de evidência de um padrão de omissão e negligência em relação à violência doméstica e intrafamiliar contra as mulheres brasileiras. O Estado brasileiro foi responsabilizado em 2001 pela Comissão Interamericana de Direitos Humanos (CIDH): "A nova legislação tem como paradigma o reconhecimento da violência contra as mulheres como uma violação dos direitos humanos" (PASSINATO, 2010, p. 219).

Atualmente a Lei Maria da Penha é reconhecida internacionalmente como um modelo de legislação para o enfrentamento da violência doméstica e familiar, com o objetivo de apresentar diretrizes para articular uma rede de atendimento, de medidas de assistência e proteção às mulheres em situação de violência. A Lei 11.340 conceitua a violência doméstica com base na Convenção de Belém do Pará, além de incluir a violência física, psicológica, sexual, patrimonial e moral. Outro ponto importante é que prevê a não aplicação da Lei 9.099/95 nos casos de violência doméstica (LAGE; NADER, 2012).

Logo nos primeiros artigos são destacados os locais de abrangência da lei: casa, trabalho, relações de afeto ou de conivência presente, ou passada. láris R. Cortês, no seu texto "Direito: A trilha legislativa da mulher" (2012) destaca em relação à Lei Maria da Penha que:

Entre as dezenas de ações importantes relacionadas a essa lei, estão: a criação de Juizados Especiais e Centros de Atendimento Multidisciplinares, a utilização de dados e pesquisas ordenados e nacionais para planejar adequadamente as ações por ela previstas e a capacitação de profissionais envolvidos com a temática da violência doméstica. Como medidas integrais de prevenção, a lei incentiva a sensibilização dos meios de comunicação social e a criação de campanhas educativas voltadas tanto ao público escolar quanto à sociedade em geral (CORTÊS, 2012, p. 277) 


\section{artigos}

Kathiusy Gomes da Silva

Pode-se analisar que a lei apresenta orientações no campo de prevenir, indicando, ao(s) Estado(s), políticas necessárias que possam evitar a violência contra as mulheres; educar quando destaca iniciativas de "sensibilização dos meios de comunicação e sociedade" por meio dos valores éticos; mudar o comportamento por meio da transformação dos valores sociais e punir aplicando as leis com máximo rigor. As medidas de urgência da Lei 11.340 estabelecem medidas protetivas, tais como, a retirada das mulheres do ambiente onde ocorre a violência e/ou que divide espaço com o agressor. Para tanto as mulheres são realocadas em ambientes seguros como casas de abrigo (que já existiam desde a década de 1980), sem prejuízos à guarda dos filhos ou de bens materiais.

A Lei também indica como deve se desenvolver o processo jurídico (fases, competências e julgamentos), assegurando à mulher o acompanhamento de um representante legal (advogado) em todas as etapas por meio dos serviços da Defensoria Pública ou da Assistência Jurídica Gratuita. A legislação fornece sugestões para a melhoria do atendimento às mulheres, como a criação de núcleos especializados de atendimento às mulheres vítimas de violência que abarcam prestação de serviço psicológico, atendimento jurídico, campanhas de enfrentamento de violência e outras.

\section{Considerações finais}

Com base nas proposições analisadas para a escrita desse artigo, notamos que a violência contra as mulheres é um problema histórico-estrutural que faz parte da sociedade brasileira devido ao tradicionalismo falocêntrico que ainda a compõe. Mesmo com o desenvolvimento legislativo, que é admirado por outras nações, o Brasil peca ao não conseguir aplicar as leis devido à falta de estrutura nas DEAMs, de 


\section{artigos}

“Em legítima defesa da honra"

funcionários, materiais, um sistema judiciário sobrecarregado que demora para realizar as investigações, prisões e ao final aplicar as penas. Outro ponto é a diminuição das penas por bom comportamento, gerando um sentimento de impunidade que está enraizado nas vítimas, quando estas sobrevivem as agressões, e em seus familiares.

Ao lidar com as fontes observei que são marcadas por períodos em que a violência contra as mulheres é tratada com maior ou menor valor de acordo com as vítimas, como percebemos em casos com vítimas famosas, que ganham espaço na mídia, como ocorreu nos assassinatos de Ângela Diniz e Daniela Perez. E casos de mulheres "comuns" ou pobres acabam sendo silenciadas.

A revista Veja trouxe em suas edições, entre 1968 e 2018, casos de violência contra a mulher, com destaque para casos com grande repercussão nacional. Contudo, ao analisar a plataforma online onde as revistas podem ser acessadas na íntegra, notamos que as edições que tratam da violência contra as mulheres possuem poucos números se comparadas a outros temas, como política ou economia. Assim, foi possível perceber que existem diversos casos que não foram contemplados nesse artigo devido aos recortes realizados, mas que merecem destaque.

Ao analisar as leis, identificamos que, apesar do desenvolvimento delas e das DEAMs, ainda existe um longo caminho para o Brasil seguir, buscando a igualdade de direitos entre mulheres e homens na efetivação das leis no cotidiano, já que nos depoimentos retirados da revista Veja percebe-se a perpetuação da impunidade e do medo que marca a história das vítimas.

Destaco que, enquanto a mulher não for valorizada como um indivíduo em mesmo nível de direito dos homens, a violência doméstica contra elas irá persistir, 


\section{artigos}

Kathiusy Gomes da Silva

não só no Brasil, mas pelo mundo afora. Por fim, destacamos que, enquanto a sociedade não condenar regularmente a violência doméstica e as demais formas de violência praticadas contra as mulheres, não há DEAM ou Lei 11.340/06 que resolvam os problemas de violência.

\section{Referências bibliográficas}

COLLING, Ana Maria. O lastro jurídico e cultural da violência contra a mulher no Brasil. XXVIII Simpósio Nacional de História: Lugares dos Historiadores - velhos e novos desafios, Florianópolis, 2015.

CORTÊS, láris Ramalho. Direito: A trilha legislativa da mulher. In: PINSKY, Carla Bassanezi; PEDRO, Joana Maria, org. Nova História das Mulheres. São Paulo: Contexto, 2012.

IZUMINO, WâniaPasinato. Violência contra a mulher no Brasil: acesso à Justiça e construção da cidadania de gênero. VIII Congresso Luso-Afro-Brasileiro de Ciências Sociais Coimbra - A Questão social no novo Milénio, 2004.

LAGE, Lana; NADER, Maria Beatriz. Violência contra a mulher: Da legitimação à condenação social. In: PINSKY, Carla Bassanezi; PEDRO, Joana Maria, org. Nova História das Mulheres. São Paulo: Contexto, 2012.

MACHADO, Isadora Vier. Da dor no corpo à dor na alma: uma leitura do conceito de violência psicológica na Lei Maria da Penha. 2013. 282 f. Tese (Doutorado em Ciências Humanas) - Programa de Pós-graduação Interdisciplinar em Ciências Humanas (PPGICH), Programa de Doutorado, Universidade Federal de Santa Catarina (UFSC), Florianópolis, 2013.

MANINI, Miriam Paula. Análise Documentária de Fotografias: leituras de imagens incluindo sua dimensão expressiva. Escola de Comunicação e Artes, USP, 2002.

_. O poder judiciário na aplicação da lei Maria da Penha. Conselho Nacional da Justiça, 2017. Disponível em http://www.cnj.jus.br/files/conteudo/arquivo/2017/10/ba9a59b474f22bbdbf7cd4f7e3 829aa6.pdf último acesso: 16/05/2018.

PASINATO, Wânia; SANTOS, Cecília MacDowell. Mapeamento das Delegacias da Mulher no Brasil. Núcleo de Estudos de Gênero Pagu, Universidade Estadual de 


\section{artigos}

“Em legítima defesa da honra"

Campinas (PAGU/UNICAMP), 2008.

PASSINATO, Wânia. Lei Maria da Penha: novas abordagens sobre velhas propostas. Onde avançamos?Civitas, Porto Alegre, v.10, n.2, 2010.

PIMENTEL, Alessandra. O método da análise documental: seu uso numa pesquisa historiográfica. Cadernos de Pesquisa, n.114, nov./2001.

PINTO, Céli Regina Jardim. Uma história do feminismo no Brasil. São Paulo: Editora Fundação Perseu Abramo, 2003.

ROCHA, Luis Fernando. A violência contra a mulher e a Lei "Maria da Penha": alguns apontamentos. Revista de Psicologia da UNESP, 8(1), 2009.

ROMANO, Rogério Tadeu. Exame de corpo de delito. Disponível em: https://jus.com.br/artigos/39204/exame-de-corpo-de-delito último acesso em: $19 / 05 / 18$

SAFFIOTI, Heleieth B. Gênero e patriarcado: violência contra mulheres. In: A mulher brasileira nos espaços público e privado. 1 ed. São Paulo: Fundação Perseu Abramo, 2004.

SANTOS, Cecília Macdowell; IZUMINO, WâniaPasinato. Violência contra as Mulheres e Violência de gênero: notas sobre Estudos feministas no Brasil. E.I.A.L., vol. 16 - n¹, 2005.

SILVA, Bárbara Garcia Ribeiro Soares da. A violência conjugal contra mulheres das classes médias do município de São Paulo. 2007. 124. Departamento de Sociologia, Programa de Pós-Graduação em Sociologia. Universidade de São Paulo, Faculdade de Filosofia, Letras e Ciências Humana, São Paulo, 2007.

SOIHET, Rachel. O corpo feminino como lugar de violência. Proj. História, São Paulo. (25), dez, 2002. 